\title{
Performance in English Skills Courses and Overall Academic Achievement
}

Jean Black

The implementation of ESL courses at universities and colleges has been based on the assumption that a threshold level of English proficiency is necessary for students to succeed at their academic work. The correlation, however, between English language proficiency and academic success has not been clearly established. This paper describes a study undertaken at Brock University which correlates performance of students in ESL courses in spoken and written English with achievement in their other academic courses. The grades received in the ESL courses were correlated with the overall academic average and the major average for the whole group and for each of three degree groups-students completing B.A., B.Sc., and B.B.E. degrees. Analysis of the data revealed a modest positive correlation between performance in written English and the overall and major averages in all groups except the B.B.E., in which there was no significant correlation. The grades for the spoken English course failed to correlate significantly with either the overall average or the major average in any of the groups. Pedagogical implications of these surprisingly low correlations are discussed, and suggestions are offered for making skills learned in ESL courses more relevant to the academic needs of students.

\section{Introduction}

Brock University offers courses in English as a Second Language to students accepted into regular degree programs, but with English skills deemed insufficient to meet the academic demands of those programs. The ESL courses were offered originally under the auspices of The Centre for English Language Programs, which evolved later into The Department of Applied Language Studies. Six half courses at three levels of difficulty are given, each level consisting of a course in spoken English and a course in written English. The courses which concern us here, EASL 140 (Spoken) and EASL 143 (Written), make up the highest level and are worth one-half credit each. (The names of EASL 140 and 143 have since been changed to APLS 1P91 and 1P90; in this study they retain the names used at the period from which the data was drawn.) The so-called ESLX courses in the two levels below the EASL level are non-credit. Upon entering the university, students are placed in one of the three levels or exempted from English language instruction altogether according to their scores on the Michigan Test of English Language and a short written essay. In order to register in EASL 140 and 143 , students must have scored sufficiently high on the 
Michigan test or have completed the second level Spoken and Written English (ESLX) courses. EASL 140 (Spoken) and 143 (Written) are the courses from which data was analysed in the present investigation.

The implementation of ESL courses at universities and colleges has been based on the assumption that there exists a threshold level of English proficiency without which students will not succeed at university studies (Snow and Brinton, 1988). The correlation, however, between English language proficiency and academic succss has not been clearly established. Numerous studies have been conducted on the relationship between TOEFL scores and grade point average (Hale et al, 1984). Two of the more recent exemplify the ambiguity typical of this type of research. Light, Ming Xu and Mossop (1987) found that the TOEFL was not an effective predictor of academic success, as measured by grade point average. Johnson (1988) achieved similar results, but interpreted them to mean that when English proficiency is relatively low, TOEFL scores can predict academic performance. The TOEFL Test Manual itself (1985) advises that there may be no relationship between TOEFL scores and academic performance when the minimum score required is fairly high. Both the studies mentioned above revealed a difference in the way in which TOEFL subscores correlated with academic achievement. Light et al found that the TOEFL Structure and Reading scores correlated significantly with the number of credit hours earned, while the TOEFL Listening subscores did not. Johnson found that Structure and Written Expression and Vocabulary and Reading Comprehension subscores correlated significantly with grade point average, while the TOEFL Listening subscores did not. Both studies also found, as might be expected, that achievement in courses heavy in outside reading and/or writing assignments was more affected by English language proficiency than was achievement in courses light in reading and/or writing.

Until the present study, no research has been conducted at Brock University on the relationship between the English language skills of ESL students and their academic performance. Instead of using TOEFL or Michigan Test scores as a measure of English proficiency, this study uses grades students received in credit EASL courses as a relative measure of their performance in two subskills of English for academic purposes. These are correlated with grades they received in their other academic courses. (It should be stressed that the EASL grades do not represent a comprehensive or absolute measure of overall English proficiency.) The results of this examination, in addition to providing factual information on the 
achievement of this population of students, shed some light on the degree of connection between the skills taught in the EASL courses and the requirements of other academic courses.

The present correlational study asks the following specific questions.

1. For all ESL students who complete degrees:

a) How do marks achieved in EASL 140 and EASL 143 correlate with each other and with their overall academic average?

b) How do marks achieved in EASL 140 and EASL 143 correlate with their average mark in their major subjects?

2. For each of three main degree groups of students-Bachelor of Arts (B.A.), Bachelor of Science (B.Sc.), and Bachelor of Business Economics (B.B.E.):

a) How do marks achieved in EASL 140 and EASL 143 correlate with each other and with their overall academic average?

b) How do marks achieved in EASL 140 and 143 correlate with their average mark in their major subjects?

\section{Method}

Subjects

The population from which the subjects were drawn were all the 136 students who registered in EASL 140 and EASL 143 in the fall term of 1982, the winter term of 1983, the spring term of 1983 , and the fall term of 1984. (Records for the three terms between spring 1983 and fall 1984 were unavailable.) This group was used because the researcher could be confident that by the time of the study (summer, 1990) the students should have completed their degrees if they were going to do so. They represented a mixed population of male and female students from Hong Kong, Malaysia, Singapore, South America, Mexico, Greece, and Libya. Of the total 136, only the 101 who had earned enough credits to receive either pass or honours degrees were selected. Of these, 20 received honours degrees, and 81 received pass degrees. The remaining 35 had incomplete records, and were thus considered unsuitable for inclusion in the study. Except for three students who received Bachelor of Administration (B.Admin) degrees, all the other 98 graduating students fell into three groups: B.A. $(n=42)$, B.Sc. $(n=$ 34), B.B.E. $(\mathrm{n}=22)$.

\section{Instruments}

At Brock, a policy of "core and context" requires each student to 
take a core of major courses and at least one contextual course from each of the Humanities, the Social Sciences, and the Sciences. The half-credit EASL courses can never be taken to satisfy the core and context requirement, but they do count as electives. Fifteen appropriate credits are required for a pass degree, twenty for an honours degree. In this study the instruments by which the students' academic achievement was measured were the overall Brock average in all credit courses except EASL courses and the average mark of the major subjects.

The instruments by which the students' English performance was measured were the grades achieved in each of EASL 140 and 143. These are primarily skills courses in English for academic purposes. EASL 140 stresses the importance of seminar participation at Brock, and, in addition to providing experience in that format, gives students practice in idioms, vocabulary, presentations, listening comprehension, and pronunciation. The course consists of three hours of seminars and one hour of language laboratory a week for approximately 14 weeks. EASL 143 includes library research techniques, the writing of term papers, in-class writing sessions, and the examination of problematic grammatical structures. The course consists of three class hours a week.

It was decided to use the EASL courses as measuring instruments rather than the lower level ESLX courses simply because the EASL courses would provide more data. As explained earlier, most nonnative English speaking visa students take the EASL courses, but several are exempted from the ESLX courses by virtue of their scores on the Michigan proficiency test.

\section{Procedure}

The marks for all students who registered in EASL 140 and 143 during fall 1982, winter 1983, spring 1983, and fall 1984 were obtained from the Department of Applied Language Studies. The 136 student numbers were then sent to the Registrar's Office, which supplied a complete transcript for each of the student numbers. Of the 136 students, 35 students did not earn enough credits for a degree and were rejected. A table was then constructed using STAT View $512+$ which showed the following information for each of the remaining 101 student numbers: Brock average, major average, EASL 140 mark, EASL 143 mark, the kind of degree obtained, and the level of the degree (whether pass or honours). Since the Brock average as it appeared on the transcript included the EASL marks, these had to be eliminated from the computation so that the table showed the adjusted Brock average (known henceforth simply as the Brock mean). 
A correlational matrix was produced for the total group of 101 students showing the coefficients of correlation for each of the following five variables: Brock mean, major mean, EASL 140 mark, EASL 143 mark, EASL 140 and 143 mean. A correlational matrix showing the coefficients of correlation for the same five variables was then produced for each of the three degree groups-B.A., B.Sc., and B.B.E. Levels of significance for a two-tailed test were calculated using critical values for Pearson product-moment correlation coefficients. Finally, the mean for each of the five variables was determined for the whole group and for each of the three degree groups. This last piece of information, relevant but not requisite to the analysis undertaken in this study, can be found in the Appendix.

\section{Results}

In general, the relationships among the variables indicate a moderate to fairly strong positive correlation between the marks achieved for EASL140 and EASL 143, and weak positive correlations (not all of them statistically significant) between the EASL marks and the Brock mean and the major mean. EASL 140 does not correlate significantly with either the Brock mean or the major mean in any of the groups, while EASL 143 correlates significantly with both the Brock mean and the major mean in all groups except the B.B.E. group. Of the three degree groups, the most correlation between EASL marks and other Brock marks occurs in the B.A. group; the weakest, in the B.B.E. group.

Table I presents the correlations among the five variables for the whole group. (In this table and the tables following, it should be noted that not all of the correlations are of interest in this study.) EASL 140 and 143 are relatively strongly correlated $r=.596, p<$ $.001)$. The EASL mean shows a small positive correlation with both the Brock mean and the major mean $(r=.234$ and $r=.222, p<$ .05 , respectively). EASL 140 shows no significant correlation with either the Brock mean or the major mean, but EASL 143 correlates with the Brock mean $(r=.273, \mathrm{p}<.01)$, and with the major mean $(\mathrm{r}=.253, \mathrm{p}<.02)$.

Beside the general weakness of all the correlations except for that between EASL 140 and 143, what is interesting here is the difference between the way in which EASL 140 and EASL 143 correlate with the Brock mean and the major mean. 
TABLE I Correlations among the five variables for the whole group

Correlation Matrix for Variables: $\mathrm{X}_{I} \ldots \mathrm{X}_{5}$

\begin{tabular}{|l|l|l|l|l|l|}
\hline & Brock Av & Major Av & EASL 140 & EASL 143 & EASL Av \\
\hline \hline Brock Av & 1 & & & & \\
\hline Major Av & .951 & 1 & & & \\
\hline EASL 140 & .152 & .148 & 1 & & \\
\hline EASL 143 & $.273^{* *}$ & $.253^{* * *}$ & $.596^{*}$ & 1 & \\
\hline EASL Av & $.234^{* * *}$ & $.222^{* * * *}$ & .903 & .883 & 1 \\
\hline
\end{tabular}

Note: 3 cases deleted with missing values

* $\mathrm{p}<.001 * * \mathrm{p}<.01^{* * *} \mathrm{p}<.02 \quad * * * \mathrm{p}<.05$

Table II presents the correlations among the five variables for the B.A. group. The EASL 140 and 143 marks correlate fairly strongly $(\mathrm{r}=.698, \mathrm{p}<.001)$. The EASL mean correlates positively with the Brock mean $(r=.343, p<.05)$, but does not correlate significantly with the major mean. Again EASL 140 fails to correlate significantly with either the Brock mean or the major mean, but EASL 143 does so with both $(r=.385, p<.01$ and $r=.337, p<$ .02 , respectively).

The fact that EASL 143 shows a stronger correlation than does EASL 140 with both the Brock mean and the major mean implies that writing for this group is a more crucial skill than is speaking. That EASL 140, even in this B.A. group, bears no significant relationship to other academic marks is, nonetheless, surprising considering the importance placed upon participation in seminars in many humanities and social science classes.

TABLE II Correlations among the five variables for the B.A. group

Corrclation Matrix for Variables: $\mathrm{X}_{1} \ldots \mathrm{X}_{5}$

\begin{tabular}{||l||l|l|l|l|l||}
\hline & Brock Av & Major Av & EASL 140 & EASL 143 & EASL Av \\
\hline \hline Brock Av & 1 & & & & \\
\hline Major Av & .928 & 1 & & & \\
\hline EASL 140 & .255 & .203 & 1 & & \\
\hline EASL 143 & $.385^{* *}$ & $.337^{* * *}$ & $.698^{*}$ & 1 & \\
\hline EASL Av & $.343^{* \cdots *}$ & .289 & .932 & .91 & 1 \\
\hline
\end{tabular}

Note: 2 cases deleted with missing values

* $p<.001^{* *} p<.01{ }^{* * *} p<.02 \quad * * * p<.05$

JEAN BLACK 
Table III presents the correlations among the five variables for the B.Sc. group. Interestingly, the correlation between EASL 140 and 143 is substantially lower $(r=.346, p<.05)$ than for either the B.A. or the B.B.E. group. Also the EASL mean fails to correlate significantly with the major mean, and only barely significantly with the Brock mean $(r=.311, p<.10)$. Again EASL 140 fails to correlate significantly with either the Brock mean or the major mean. EASL 143 correlates significantly with the Brock mean $(\mathrm{r}=.392, \mathrm{p}<.05)$, and only barely significantly with the major mean $(\mathrm{r}=.299, \mathrm{p}<.10)$.

Why the correlation between EASL 140 and 143 should be so much weaker in this group than in the B.A. and B.B.E. groups is not evident. No doubt EASL 143 shows a higher correlation with the Brock mean than with the major mean because the major courses would be science courses and therefore more independent of writing skills than the contextual courses, which would be social science and humanities courses.

TABLE III Correlations among the five variables for the B.Sc. group

Correlation Matrix for Variables: $\mathrm{X}_{1} \ldots \mathrm{X}_{5}$

\begin{tabular}{||l|l|l|l|l|l||}
\hline & Brock Av & Major Av & EASL 140 & EASL 143 & EASL Av \\
\hline Brock Av & 1 & & & & \\
\hline Major Av & .945 & 1 & & & \\
\hline EASL 140 & .134 & .15 & 1 & & \\
\hline EASL 143 & $.392^{*}$ & $.299^{* *}$ & $.346^{*}$ & 1 & \\
\hline EASL Av & $.311^{* *}$ & .269 & .842 & .798 & 1 \\
\hline
\end{tabular}

Note: 1 cases deleted with missing values

- $p<.05 \quad * p<.10$

Table IV presents the correlations among the five variables for the B.B.E. group. The correlation here between EASL 140 and 143 is moderately strong $(\mathrm{r}=.699, \mathrm{p}<.001)$ and almost identical to that of the B.A. group. None of the other correlations approaches significance.

This is perhaps the least anticipated result of all. Business students, like others, are required to satisfy the requirements of core and context in their course selections, and some of their major 
courses would appear to be at least as language dependent, if not more so, than those taken by B.Sc. students. Neither can the weaker correlations for the B.B.E. group be associated with weaker English skills in general or with wildly anomalous Brock or major means. In fact, Table $\mathrm{V}$ in the Appendix reveals that B.B.E. students achieved a higher EASL mean than did the other two groups, slightly higher Brock and major means than those of the B.A. group, and lower Brock and major means than those of the B.Sc. group. We are left with the possible explanation that the correlations are lower here precisely because the English proficiency of the B.B.E. group is higher. This would be consistent with Johnson's finding that the lower the language proficiency, the more important the role it plays in academic success. Whatever the reason, it appears that the English skills of the B.B.E. students have practically no correlation with their performance in other courses.

TABLE IV Correlations among the five variables for the B.B.E. group

Correlation Matrix for Variables: $\mathrm{X}_{1} \ldots \mathrm{X}_{5}$

\begin{tabular}{||l||l|l|l|l|l||}
\hline & Brock Av & Major Av & EASL 140 & EASL 143 & EASL Av \\
\hline \hline Brock Av & 1 & & & & \\
\hline Major Av & .946 & 1 & & & \\
\hline EASL 140 & .122 & .214 & 1 & & \\
\hline EASL 143 & .152 & .274 & $.699^{*}$ & 1 & \\
\hline EASL Av & .148 & .264 & .925 & .918 & 1 \\
\hline
\end{tabular}

Note: 3 cases deleted with missing values

- $\mathrm{p}<.001$

\section{Conclusion}

Results of the present investigation show that while there is a fairly strong positive correlation between performance in the spoken and written English skills courses themselves, correlations between performance in those courses and other academic courses is small. ${ }^{1}$ These results are not entirely unexpected. Correlations between TOEFL scores and academic performance in the studies of Light et al (1987) and Johnson (1988) are similarly small. To summarize the more noteworthy results:

1. EASL 140 and EASL 143 correlate fairly strongly. It appears that speaking and writing are inherently related, and/or the courses 
are designed with coordinated objectives and marking schemes in mind. The anomoly here is the B.Sc. group, for which the correlation between EASL 140 and 143, while still significant, is much smaller than for the other groups.

2. While EASL 143 correlates very modestly but significantly with both the Brock mean and major mean in all groups except the B.B.E., EASL 140 does not correlate significantly with either the Brock or major mean in any of the groups. The failure of the Listening subscore of the TOEFL to correlate with grade point average is also noted in Light et al (1987) and Johnson (1988).

3. In the B.B.E. group, EASL 140 and 143 both fail to correlate with either the Brock mean or the major mean. As noted earlier, this group has the highest EASL mean, which may account for the low correlations.

We must be careful in interpreting these and all the other results.

What cannot be inferred from the results:

1. That a causal relationship exists between performance in EASL courses and performance in other courses. This means that even when correlations are positive and significant, we cannot conclude that a mark in an academic course is the result of a mark in an EASL course.

2. That students do not learn much English in EASL courses. They may learn a great deal; this study does not attempt to examine what they learn. (See point 3 under "What can be inferred".)

3. That students do not need to take English skills courses. A lack of correlation between grades in EASL courses and grades in other academic courses does not mean that students are all proficient enough in English. The ongoing challenge is to design skills courses that meet the needs of the students in the various academic environments in which they find themselves.

What can be inferred from the results:

1. That performance in EASL 140 and even 143 is not a very good predictor of performance in other academic subjects--and vice versa. Even with one of the strongest correlations of all $(\mathrm{r}=.392, \mathrm{p}<.05)$ when EASL 143 is correlated with the Brock mean of the B.Sc. group), we are accounting for only about $15 \%$ of the variance between the two variables. In other words, $85 \%$ of the variance may be attributed to other factors such as academic aptitude, motivation, organizational skills, adaptability, emotional security, etc.

2. That for ESL students, writing skills are significantly better indicators of performance in academic courses than are oral/aural 
skills, this in spite of the emphasis Brock places on the importance of the seminar system in undergraduate courses. This finding is consistent with that of Light et al (1987) and Johnson (1988) that listening is not as important a factor in academic success as might have been expected.

3. That skills being taught and evaluated in EASL 143 and particularly in EASL 140 have limited relevance to the requirements of other courses. Either the skills learned and evaluated are not relevant and therefore not transferable; or they are relevant, but students simply fail to transfer them. This is an important point and warrants further inquiry. Any review of objectives, materials, and methodologies for EASL courses would need to take both possibilities into account. (Of course, when speaking of the transfer of skills, it must be kept in mind that the EASL courses are not necessarily among the first courses taken at Brock. Typically, students take the ESLX courses in their first term along with two or three academic courses. By the time they enroll in the EASL courses, they may have already taken two or three or more academic courses.)

The question of how best to help ESL students learn the English they need in order to survive academically continues to challenge administrators, curriculum designers, and instructors alike. Teaching models designed for general communicative competence do not necessarily work well for academic competence. In view of the results reported above, those models for teaching academic competence which attempt to build in the closest connection possible with the content courses for which the students need English appear to hold the the most promise for improving the correlations between skills learned in ESL classes and performance in other academic courses-if, indeed, that is a desirable goal. The content-based models mentioned below, all predicated on a close association of English skills with academic functions, are worthy of consideration. Wesche (1985) discusses the manner in which French/English immersion courses in content areas such as introductory psychology are managed at the University of Ottawa. Chamot, Uhl, O'Malley, and Michael (1987) describe their Cognitive Academic Language Learning Approach for elementary and secondary levels. Snow and Brinton (1988) analyse the effectiveness of the Adjunct model implemented at UCLA.

At institutions where ESL courses are independent of academic courses, as they are at Brock, there are still many ways to relate English instruction to academic need. A detailed model for teaching EAP goes beyond the scope of this paper, but the 
following suggestions are offered. They are certainly not new; some have been experimented with to a limited extent by this researcher and other instructors.

1. First, it would seem appropriate to find out as much as possible about the requirements of academic courses in the degree programs in which ESL students are most typically enrolled. Interviews could be conducted with professors of the required courses in the various programs. Professors of some of the most popular contextual courses could also be interviewed. Instructors of laboratory classes, tutorials, and seminars should not be neglected since it is in these situations that oral/aural skills are most crucial.

2. The ESL courses could then be designed with these academic requirements in mind. This does not imply that the ESL instructor must try to be an expert in every field as well as her own. She could, however, ensure that between some of the exercises she assigns and some of the requirements of academic courses there is an overlap of language skills. For example, there is little point in teaching ESL students to write an essay that would satisfy a professor of English literature when very few ESL students take English literature. As another example, this author was told by an instructor of computer science that students need practice in writing short, precise answers to examination questions.

3. For the language laboratory, sections of actual lectures given at Brock University could be brought to class for analysis. These could be taped either by the professor involved, the ESL instructor, or the students themselves. Taped, informal interviews with professors concerning their academic expectations could also be valuable-both as sources of information and as models of the language. J. Cleland (1990) has reported on a successful experiment in Brock's Intensive English Language Program in which taped materials-popular songs, commercials, newscasts, interviews-were brought to the lab class by students and exploited for listening comprehension and pronunciation practice. This an example of how activities designed for a communicative model might be adapted to suit an academic model.

The results of this investigation illustrate how little we yet understand about the role English skills play in academic performance. Anything we can do to bring some light to that $85 \%$ area of darkness indicated by the statistics is worth trying. 


\section{NOTES}

1. Aside from the reasons that have already been suggested, there is a statistical problem that might partly account for the weak correlations. Of the 101 students who completed degrees, 12 failed on their first attempt(s) at passing EASL 140 and/or 143. Some students required as many as four attempts! On other courses as well, some students required more than one attempt to pass. On the transcript, however, only the passing grades are counted in the overall average and the major average, and they were the grades used in this study. In other words, for these students, the marks used reflect less accurately their true achievement in either the EASL courses or the other courses than they do for those students who passed on their first attempts. It is possible that if the analysis had been able to take into account the several attempts required to pass some courses, the correlations would have been improved.

\section{ACKNOWLEDGMENTS}

I am grateful to John Black for assistance in the application of the SAT View $512+$ program and for general statistical advice. 


\section{APPENDLX}

Means for the whole group (Pass/Honours)

Mean

S.D.

$\mathrm{N}$

Missing

Brock Mean

Major Mean

66.81

5.49

98

3

EASL 140

66.76

6.54

101

66.26

8.59

98

63.99

7.89

99

EASL Mean

65.07

7.35

98

3

3

Means for the B.A group

Mean

S.D.

$\mathrm{N}$

Missing

Brock Mean

Major Mean

EASL 140

64.22

4.30

40

5.72

42

65.03

1.43

40

63.15

7.00

40

64.09

7.84

40

2

0

2

2

EASL Mean

Means for the B.Sc. group

Mean

S.D.

$\mathrm{N}$

Missing

Brock Mean

70.46

5.80

33

6.40

34

EASL 140

71.21

7.78

33

63.68

7.15

34

64.79

6.05

33

1

0

1

0

EASL Mean

Means for the B.B.E. group

Mean

S.D.

$\mathrm{N}$

Missing

Brock Mean

65.59

4.00

22

0

Major Mean

64.91

4.27

22

68.86

9.10

22

65.27

8.69

22

EASL Mean

67.07

8.20

22

0

0

0

0 


\section{REFERENCES}

Chamot, A. and O'Malley, J. M. (1987). The cognitive academic language learning approach: A bridge to the mainstream. TESOL Quarterly, 21, 227-249.

Cleland, J. (1990). Today is Keiko's day: Using student-provided materials for listening comprehension. Presentation at the 18th Annual Conference of TESL Ontario.

Educational Testing Service. (1985). TOEFL Test Manual. Princeton, NJ: Author.

Hale, G. A., Stansfield, C. W. and Duran, R. P. (1984). Summaries of studies involving the test of English as a foreign language, 196382. Princeton, NJ: Educational Testing Service.

Johnson, P. (1988). English language proficiency and academic performance of undergraduate international students. TESOL Quarterly, 22, 164-168.

Light, R. L., Xu, M., and Mossop, J. (1987). English proficiency and academic performance of international students. TESOL Quarterly, 21, 251-261.

Snow, M. and Brinton, D. M. (1988). Content-based language instruction: Investigating the effectiveness of the adjunct model. TESOL Quarterly, 22, 553-574.

Wesche, M.B. (1985). Immersion and the universities. CMLR, 41, 931-940.

\section{THE AUTHOR}

Jean Black has a M.A. in English and a B.Ed. in T.E.S.L. She has taught English literature at the University of Saskatchewan and at Niagara College. Since 1986 she has been teaching ESL in the Department of Applied Language Studies at Brock University. She has also taught ESL at the University of Essex, England where she worked as an exchange teacher in the summer of 1988. Her teaching focus is on oral/aural skills. 


\section{In the Classroom \\ En Classe}

This section of the Journal is specifically concerned with the second language classroom. It features:

1) descriptions of teaching techniques and methodologies.

2) practical classroom activities, and

3) teachers' reflections on classroom practice.

Cette section de la Revue se concerne specifiquement avec la classe de langue-seconde. Elle contint:

1) descriptions de methodes et techniques d'enseignement.

2) activités pratiques pour la salle de classe, et

3) réflections d'enseignant/es sur la salle de classe. 